\title{
Gestión local, espacios turísticos y desarrollo. Cinco modelos para armar (sur de Lima)
}

\author{
Y los viajes a Lima se hacian por barco \\ $Y$ demoraban toda una noche. \\ Bajo esa hermosa estrella dei Sur. \\ Ahora un viaje dura dos horas y se hace por \\ auto \\ -Comité $N^{\circ} 1$ y $N^{\circ} 10$ de Transportes- \\ $y$ uno piensa que dos horas es mucho tiempo \\ perdido... \\ Enrique Verástegui, 1971.
}

\section{Fernando Armas Asin}

El presente artículo busca, a partir del estudio histórico, social y económico de las provincias de Cañete y Yauyos, describir la formación de espacios turísticos y las respuestas o actitudes de sus diversos pueblos, ordenándolos en modelos de análisis según características, para observar la manera cómo conciben el patrimonio, el turismo y, sobre todo, el desarrollo económico y social en función de los retos a que son sometidos ${ }^{1}$.

\footnotetext{
1 Este trabajo es una condensación del capítulo 4 de un informe efectuado para el Instituto de Investigación de la Escuela de Tunsmo y Hoteleria, de la Universidad de San Martin

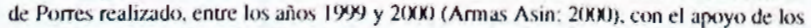
asistentes Fabiola Signori y Christian Antúnez, a quienes se agradece su paricipación.
}

\section{Modelo uno}

Chilca se encuentra situada en la parte baja de la cuenca del mismo nombre, de clima desértico y con escasas tierras agrícolas, es un punto de confluencia del eje litoral (Lima-Cañete) y transversal (Pachacamac-Chilca-Piedra Grande-Huarochiri) de la cuenca hidrográfica. Debido a su escasa agricultura, los chilcanos usaron de hoyadas y hoy de pozos tubulares para obtener agua del subsuelo. Ello determinó cultivos como el higo, la vid y algunos otros frutos. Como resultado de la Colonia y los derroteros republicanos, la cabecera de la cuenca terminó integrándose a Huarochirí (Santo Domingo de los Olleros). Un viejo camino afirmado llega hasta Piedra Grande, uniendo esa zona al litoral. 
La creación de la provincia de Cañete en 1821 , incluyó al distrito de Chilca, que llegaba hasta Pucusana y San Bartolo. La fractura de esos lugares en beneficio de la provincia de Lima (como fruto de la expansión urbana y del circuito de playas, a mediados del siglo XX) no afectó sus vínculos con ella, que incapaz de satisfacer la creciente demanda de una población desempleada, tuvo y tiene en los mercados laborales de Pucusana, San Bartolo e incluso Lurín, sus alternativas más importantes. En un estudio que hicimos en el pueblo de Chilca, sobre 100 jóvenes de 15 a 30 años, resultó que 56 trabajaban fuera del pueblo: 21 en los alrededores (agricultura, pesca, servicios) en tanto 13 lo hacían en Pucusana, 5 en Lurín, 3 en Mala y Bujama, 7 en San Bartolo, $u$ otros pueblos de playa, y 8 en la ciudad de Lima (encuesta de mercado laboral en Chilca: 1999). Estos jóvenes salían temprano de sus casas y regresaban muy tarde, haciendo hasta una hora de viaje, utilizando la carretera Panamericana Sur.

De modo tal que, con agricultura pobre y pesca artesanal, tuvieron y tienen que mantener estrecha relación con zonas aledañas para satisfacer sus crecientes necesidades laborales y comerciales en general. La creación de la Panamericana Sur en 1937 y la de doble vía, Lima-Pucusana en 1967 con su prolongación a Bujama en 1983 y a Cerro Azul en 1987, acentuaron esta condición. Creemos que el fortalecimiento de esta tendencia litoral permitió al pueblo y distrito de Chilca evitar, como en la cabecera de la cuenca, una pérdida neta de población, afirmándose incluso un incremento notable basado en la condición de ser parcialmente un pueblo-dormitorio con alternativas laborales en un radio de $70 \mathrm{~km}$. Esta condición de pueblo-dormitorio, con la carretera como eje, la comparten Mala, Bujama, San Bartolo, Pucusana, Punta Negra y Punta Hermosa, y, en menor medida: Cerro Azul, Cañete y Chincha; habiéndose establecido un sólido corredor litoral de intercambio con un núcleo de desarrollo, atracción y regulación en Lima. Este tipo de organización micro espacial, frecuente en otras partes del mundo - creación de periferia de grandes urbes o de regiones con ciudades intermedias -, ha permitido contra-balancear el declive de la agricultura como gran mercado laboral en la zona.

Sobre estas condiciones el distrito y pueblo de Chilca ha ido construyendo su historia. Hasta inicios de 1980 seguía siendo conocido como un lugar de pequeños propietarios agrarios, preferentemente productores de higos, y también como un lugar de esforzados pescadores. Los alcaldes poco o nada se habían preocupado de otras tareas sino de sortear las condiciones de pobreza, reflejada en ausencia de agua potable y alcantarillado. Ya entonces los que no podían conseguir empleo en el corredor litoral se establecían en Lima (ONERN: 1976).

No había visitantes en Chilca, salvo los paseos dominicales de familias de Lima, Lurín o Cañete. Como novedad existían las inversiones en granjas avícolas y una fábrica de cemento que por esos años paralizó sus operaciones, ambas dentro del corredor litoral. El poeta Antonio Cisneros, en Crónicas del Niño Jesús de Chilca, graficó muy bien el panorama: los jóvenes saliendo muy temprano a las faenas de pesca, o a trabajar a veinte minutos o una hora de viaje, mientras los viejos soñaban y se refugiaban en olor a incienso en la procesión y en la cofradía del Niño Jesús.

Sin embargo, existían las lagunas medicinales de Las Salinas, además del templo católico y el sitio arqueológico de Bandurria.

La Iglesia de Nuestra Señora de la Asunción es el único monumento católico de interés. Fue mandada construir en 1737 por sacerdotes agustinos, encargados de la Doctrina de Chilca, aunque fueron los franciscanos quienes la inauguraron, al poseer luego dicha Doctrina. En 1900 sufrió un incendio que debió destruir buena parte del techo y presbiterio y quedó entonces semi abandonada. En 1944 fue declarada monumento histórico por el INC, aunque nada ocurrió hasta 1970 en que el padre Agapito Muñoz empezó a hacer reparaciones mínimas, pero el terremoto de 1974 acabó con sus esperanzas, pues se dañó la estructura y fue definitivamente abandonada. En 1976 se construyó una capilla y casa parroquial aledañas para atender las necesidades pastorales de la zona.

En el caso del manantial medicinal de Las Salinas, si bien era visitado por los chilcanos y por personas de Lima y Cañete, era en la práctica un lugar desatendido (el viejo camino de herradura conectaba a Chilca con ese lugar) y la única concentración importante de gente se daba cuando los que vivían en los alrededores celebraban la Fiesta de La Cruz (mayo). En cuanto al sitio arqueológico de Bandurria y alrededores, las excavaciones de Frederic Engels y de la Universidad de Agraria de La Molina, habían descubierto en 1967 basurales y al- 
deas de horticultores semi nómades, pero ni para los chilcanos ni para los escasos visitantes significaba un centro de atracción.

Así pues, hasta la década del 80 , no existió un flujo de visitantes relevante ni una intencionalidad de promoverlo por parte de alcaldes o chilcanos en general. Fue en el marco de la consolidación del corredor litoral (nueva Panamericana en 1983, uso de más playas al sur de Lima, afluencia masiva de campistas y búsqueda de urbanizaciones de veraneo) que familias en autos o pasajeros en omnibuses, empezaron a detenerse para comprar higos a la orilla de la carretera en Chilca o a visitar Las Salinas, o que los integrantes de RAMA, luego de sus investigaciones extra sensoriales, se detuvieron en algún momento. Este agregado de visitantes tangencialmente creado fue el que motivó, al lado de un creciente interés por la promoción del turismo, a que las autoridades del lugar trataran de activar una tarea de promoción sobre lo ya existente: Las Salinas, el templo, los higos y Bandurria.

En 1978, el sacerdote español Juan Carlos Antelo empezó a reconsiderar la idea de restaurar el templo y logró que la constructora SAUBA, del arquitecto Luis Orrego Villacorta, hiciera un estudio estructural. Con financiamiento de Manos Unidas, AECl y Cooperación Popular se hicieron reforzamientos y demoliciones que representaron un $50 \%$ del avance total de la obra (Napa: Entrevista 13-IX-1999). En 1998 L. Napa, párroco actual y chitcano de nacimiento, se trasladó a vivir cerca del templo y tomó la determinación de concluir su restauración. Constituyó entonces el Comité Pro Templo, responsable por la captación de fondos para terminar las obras, siendo él un veedor de la labor. Así empezó la fase final de la restauración, en la que actualmente se encuentran (Informe del arquitecto César Lévano: 1998), obteniendo fondos de agencias internacionales, del municipio, del gobierno, de universidades y por medio locales (rifas y bingos).

En cuanto a Las Salinas, en tiempos del alcalde Manuel La Rosa (1993-1995) y ante el incremento relativo de visitantes, se construyeron baños, lo que coincidió con una mayor inversión de particulares en restaurantes y casas albergue en los alrededores de los manantiales. El regidor José Luis Cuya se contactó con un grupo de jóvenes chilcanos para que coordinaran la celebración del Festival del Higo y lo promocionaran en relación con Las Salinas. Se hicieron pancartas y carteles y se trató de que asistieran los vendedores de higos frescos y de dulces, pero la iniciativa fracasó. Ciertamente tampoco era grande la afluencia de visitantes (promedio diario/1999: 19) para convencer a los vendedores tradicionales de la carretera (donde la afluencia es mayor) para agruparse en un campo ferial en Las Salinas. Sin embargo, nótese el interés por reunir en un sólo lugar higos y manantiales, dos de los cuatro productos de Chilca. Luego, durante la administración del alcalde Eugenio La Rosa (1996-98) se hizo un cerco a Las Salinas, mientras que frente a los problemas del mal camino, el actual alcalde Numa Rueda (1999), con apoyo gubernamental de CORDELICA, realizó su nivelación. Las Salinas actualmente cuenta con restaurantes, una docena de albergues y un sistema de transporte a la zona (tres comités de moto taxis, en la ruta Chilca-Las Salinas). Sin embargo, existe un mal servicio de hoteles que son también restaurantes-albergues, negocios múltiples para sobrevivir. La curva de visitantes es atípica, hay exceso de capacidad instalada y oferta, y el público demandante es de estrato popular, lo que representa una limitación en términos de mejoramiento de calidad y efecto multiplicador en la economía.

El Festival del Higo se realiza desde el año 1988 gracias a la sugerencia que recibió la administración edilicia de Lizardo Caycho (1987-1989) por parte del personal de la comunidad "Villa Federico Ozanam", que había construido un hogar para niños abandonados. La idea fue mostrar la producción del higo de Chilca, presentándose hasta la actualidad en forma de feria artesanal en la Plaza de Armas del lugar. Sin embargo, esta idea sugerente nacida dentro del interés por hacer festivales como forma de atracción de visitantes ha mostrado serias limitaciones. Tanto en 1999 como en el 2000 el festival sólo atrajo a una veintena de pequeños comerciantes y a un flujo muy pobre de visitantes. Mala infraestructura, poca promoción, deficiencia de calidad de productos, son los problemas que han limitado su desarrollo.

Respecto a las playas en manos privadas, a manera de clubes o asociaciones, sólo repercuten en la economía chilcana con su escasa demanda de empleos para guardianía ya que la mayoría de compras de insumos y alimentos se realizan en Lima o Lurín. Pero Chilca cuenta además con $7 \mathrm{~km}$. de playas abiertas, que han sido tradicionalmente 
el lugar de veraneo de sus pobladores. Empero, la carencia de un camino afirmado y la competencia de playas y lugares con mejores servicios en el corredor litoral - tanto como el litigio permanente del municipio por asuntos tributarios con la Comunidad de Chilca, que es copropietaria de la zona-, limitan su porvenir. En cuanto al sitio de Bandurria, bajo administración del INC, no ha conocido mayores mejoras en términos de infraestructura.

Así pues, si bien ha existido una demanda agregada de visitantes en estos años, como consecuencia de la consolidación del corredor litoral, no ha sido ni muy numerosa, ni socio económicamente interesante como para sostener un esfuerzo de transformación del lugar. Creemos que ni Las Salinas, ni el templo o el sitio de Bandurria son, de por sí, polos de atracción de visitantes interesantes. Las Salinas tiene serios problemas en infraestructura, calidad de servicios y facilidades sanitarias. En términos académicos se sabe que un lugar medicinal no es por sí solo un polo de atracción como tampoco lo son Bandurria o el templo, ya que templos en mejores condiciones son numerosos. Tampoco las playas pueden cumplir esa función: son contaminadas, cerca al pueblo, y de poco atractivo natural comparadas con otras del litoral. El gran público que en verano se mueve por la Panamericana Sur (de los sectores socio-económicos $A, B \circ C 1$ ) prefiere otras posibilidades. Chilca posee pocos atractivos (Armas Asin 2000: Inventario patrimonial de la cuenca de Chilca. Anexos 4) y los cuatro antes mencionadas son las únicas posibilidades reales, pero de un visitante de perfil medio-bajo y popular inconstante. Esos atractivos deben ser vistos como complementarios y no como polos en sí. Complementarios en función a otras posibilidades que brinda el corredor litoral como en la práctica está sucediendo con las familias que se detienen a comprar higos o ver Las Salinas en su camino a Cañete, Chincha o de regreso a Lima.

Sin embargo, una reconstrucción del pasado y una visión de la realidad actual ha llevado a alcaldes y chilcanos en general por otras vías, ignorando un hecho que cotidianamente está sucediendo en el corredor litoral. Al revisar la literatura hecha y promovida por el municipio desde 1990 , tanto como entendiendo las diversas entrevistas, surge una noción de desarrollo autónomo $y$ de fe en el patrimonio y sus posibilidades turís- ticas (Castro Chero: s.f.; Chilca: 1999, s.f.). En su deseo de promoción surge el paroxismo por El Hombre de Chilca, basado en los pocos restos y casas encontradas por Engels en 1967. Hay entonces un hombre chilcano de 6 mil años de antigüedad. Pero éste no atrae turistas ${ }^{2}$. Tampoco las lagunas medicinales. Todos los alcaldes (Napa: Ibíd) han soñado con atraer multitud de turistas sólo y exclusivamente a Chilca. El actual planea un camino que una Las Salinas con las playas y con la Panamericana; con un Festival del Higo que conecte a productores (¿hay grandes productores de higos que puedan cumplir con convenios de producción?) con distribuidores de Lima; y, en fin, con una serie de medidas que refuercen el concepto del ser chilcano (Rueda: Entrevista 13IX-1999).

A nuestro entender el entusiasmo por el pasado y la lectura del patrimonio que tienen (supravalorado) ha llevado a no comprender que éste es interesante en función de una realidad mayor (el corredor). Dadas las circunstancias actuales es imposible pensar en otras condiciones del desarrollo turístico. Pero también esta limitación frustrante, que es el típico caso de un modelo no implementado plenamente por tener supuestos inviables (es decir, las lecturas tan localistas), ignora la gran posibilidad de las pampas de Chilca y sobre todo de su cabecera hoy incomunicada. Pensar en una realidad de la cuenca implica empezar por entender las realidades mayores, salirse de los límites distritales y de una tutela municipal tan vital como nociva.

La cuenca y el corredor litoral, el último desarrollado anticipadamente, es con todo, un espacio amorfo. De él participan activamente los balnearios y pueblos al sur de Lima hasta Bujama. $Y$ en un plano menor Cerro Azul, San Luis, San Vicente de Cañete y Chincha. Sobre este corredor se ha formado un circuito con un patrimonio que es entendido como funcional al modelo. Lectura del pasado y evidencia material contribuyen a este papel del litoral, con sus elementos complementarios. Pero así como Chilca existen otros pueblos que han tratado de crearse una visión distinta del pasado y de la promoción turística, entrando en contradic-

\footnotetext{
Nos referimos a yque, académicamente. restos de precencia humana de weis mil años de antigiedad. no implican la existencia de hombres peruanos o chilcanos, invencione conceptuales de hace dos o tres siglos.
} 
ción con este espacio creado. Uno de ellos es San Vicente.

San Vicente de Cañete, como distrito y capital de provincia, es una ciudad relativamente joven. Recordemos que su origen se remonta a la existencia de antiguas encomiendas de españoles en la zona del valle y en Lunahuaná, en el siglo XVI. La importancia del valle, abastecedor de productos agrícolas de la ciudad de Lima, determinó la fundación de una villa y la erección de un corregimiento sobre las actuales provincias de Cañete y Chincha.

La villa estaba originalmente emplazada entre el viejo puerto de Cerro Azul y San Luis, con el nombre de Santa María de Cañete. Debido a ataques de piratas y a problemas sísmicos se trasladó, a fines del siglo XVIII, al interior del valle -actual ubicación- con el nombre de San Vicente Mártir. El anterior emplazamiento permaneció con el nombre de Pueblo Viejo hasta que en el siglo XIX se lo erigió como distrito y pueblo de San Luis Obispo. Pero, Pueblo Nuevo o San Vicente, ciudad del siglo XVIII, no conserva la infraestructura de ésa época. El templo de fines del XVIII se demolió en los años sesenta para construir la moderna catedral, y el edificio edilicio es de mediados de este siglo. Un viejo convento agustino sirvió como albergue de la comisaría hasta que sus últimos restos desaparecieron con el terremoto de 1974. De esta manera la actual ciudad de San Vicente es moderna y sus casas más antiguas datan de los años 40 debido al natural fenómeno de reemplazo de infraestructuras que han hecho las familias del lugar. Actualmente, este centro administrativo de la provincia, da la impresión de una gran urbanización, tranquila y apacible.

Desde el punto de vista del turismo no ofrece mayor atractivo, salvo el de ser una ciudad de tránsito hacia otros lugares. Creemos que en esta perspectiva debe analizarse la actual paradoja sobre la identidad de San Vicente y su gente, ya que se trata de una ciudad moderna y sin tradición histórica. Sus habitantes lo saben y, desde un punto de vista sociológico, se asumen más cosmopolitas que sus paisanos de otros distritos. El problema mayor, e histórico, radica en que las autoridades de San Vicente, desde hace dos siglos, han tratado de sentar una tradición del pasado basada en una noción de su carácter central al interior de la provincia. A la vocación por esforzarse, a nivel de cuenca, y de hacer prevalecer el papel del valle, se une el papel rector de San Vicente. Lo que se puede apreciar en la folletería consultada de la primera mitad del siglo $X X$.

Sin embargo, San Vicente se inventó una tradición histórica hace apenas treinta años (Cárdenas: 1999; Correa: 1978; Luyo Sánchez: 1981) en función de la necesidad de afrontar un futuro económico y social cambiante. Frente a un mercado laboral basado en el sector agrario y de servicios, la segunda parte del siglo XX trajo consigo la reforma agraria (1969) y la evidencia de la incapacidad del sector de solventar los empleos que se necesitaban. La modernización (luz eléctrica, agua, desagüe) fue acompañada de una toma de conciencia sobre la generación de nuevos mecanismos para reorientar las necesidades económicas y sociales.

En efecto, en 1970, en tiempos del gobierno municipal del residente español Alfredo del Toro Moreno (1967-1973) se creó la Semana Turística de Cañete. Antes de 1970 San Vicente, como ciudad y distrito, celebraba de manera modesta la fiesta religiosa de San Vicente Mártir (22 de enero) con una procesión y fuegos artificiales. El 30 de agosto, fecha recordatoria de la fundación de una villa (1556) cuyo nombre y lugar eran ya inexistentes (Santa María de Cañete), no se celebraba, salvo por sesiones solemnes edilicias. Tampoco se conmemoraba el 4 de agosto, fecha de la creación de la Provincia (1821). Fue en 1970 que el alcalde, sus regidores y asesores decidieron, como una estrategia de captación de la atención nacional, hacer una Semana Turística. El plan era ambicioso y en cierto modo ha sido el único realmente consistente de cuantos se han intentado en ese municipio en el siglo XX. El objetivo central era atraer turismo nacional (particularmente limeño) hacia la ciudad y provincia de Cañete. Era la primera vez que en el sur chico se daba una orientación turística desde el punto de vista de la planificación. Era también la primera que se hacía un plan a largo plazo.

Debemos recordar el momento histórico. Era la época en que los municipios más solventes empezaban a hacer planes al 2000 desde el punto de vista de la planificación urbanística y socio-económica (Plan Lima 2000 de esos años). El alcalde de Cañete, empresario agro industrial español imbuido en estas ideas, y consciente de la experiencia inicial de España en la materia (la agresividad con que en los años sesenta empezó a promocionar su turismo), 
concibió algo análogo para su provincia. También es bueno destacar el contexto nacional, ya que desde 1969 empezaba la reforma agraria en el Perú y un nuevo escenario económico se abría y la clase media alta cañetana migraba a Lima.

Si bien es justo señalar que hubo una idea de futuro al concebir la promoción del turismo en la provincia, el concepto se planteó como un proyecto de alcance provincial y no distrital. El grupo de asesores del alcalde era consciente de la debilidad de San Vicente en materia de tradición histórica. Así, basándose en el hecho de que la Municipalidad debía beneficiar al conjunto de la provincia con este plan, se creó la Semana Turística de Cañete, con el 30 de agosto (día no laborable nacional al ser fiesta de Santa Rosa) como día central, recordando la fundación española de la Villa Santa María de Cañete, que pasó a ser el aniversario provincial.

La Semana Turística de Cañete creó dos eventos sobre el cual basar su éxito. El primero fue una Feria Agropecuaria y Artesanal que durara toda la semana (extendida luego a una semana antes, como fecha de inicio) donde se mostraba la producción de los artesanos de la provincia y la producción agropecuaria de los valles. Tenía el objetivo de atraer personas de Lima y de la misma provincia. El segundo fue un Festival de Arte $\mathrm{Ne}$ gro, con la idea de favorecer la difusión del arte de Cañete al Perú. Se concibió como un evento dedicado exclusivamente a crear una demanda limeña. Por ello, el Municipio asumió su organización, y se creó como un festival de concurso de bailes negros, con énfasis en los llamados ritmos "calientes". Captar un público masivo ofreciéndoles un espectáculo de ritmos y diversión, con venta de licor incluido, era la idea primordial. Desde el inicio se descartó ofrecer un Festival del Arte Negro, entendiendo el arte en toda su expresión (plástica, musical, teatral). Tampoco en 1970 se podía esperar una madurez en estas ideas, y por cierto, hubiese sido un fracaso en términos monetarios. Hay que anotar que era la primera vez que se hacía un espectáculo de ese tipo. Por otro lado, las ideas han cambiado mucho y se sabe que un negocio de promoción del arte en su concepto amplio, dependiendo cómo se oferte y bajo qué condiciones, sí puede obtener un éxito económico. El día 30 se complementó con un desfile cívico-escolar.

Así, la Semana Turística se lanzó en 1970. La primera Feria Agropecuaria y Artesanal se hizo en la Plaza de Armas de la ciudad con participación de productores, comerciantes que vendían ropa, además de juegos de entretenimiento y venta de artesanías de otros lugares (del norte del Perú, por ejemplo). El Municipio lotizó el lugar de la feria y dispuso infraestructura desarmable (ángulos ranurados, esteras e iluminación especial) que compró para esa y las siguientes ediciones. Desde el punto de vista de la infraestructura, ésta fue bien concebida, al proporcionar a los vendedores y consumidores una zona ferial limpia, aseada y accesible. Pero pronto se vieron las deficiencias ya que el público captado fue sólo de San Vicente y alrededores. No hubo captación de turistas salvo para el día del Festival de Arte Negro. Y por otro lado, se vio claramente que los productores artesanales y agropecuarios no eran tan numerosos como se esperaba. En el caso de los artesanos, los existentes ni siquiera eran de la provincia.

En cuanto al Festival de Arte Negro, con las características reseñadas, se realizó el sábado anterior al día central (30 de agosto) en el estadio Roberto Yáñez (como se hace hasta el día de hoy) con gran éxito ya que llegaron muchos jóvenes y familias de Lima. Se les ofreció diversión garantizada por un precio alto para la provincia, pero asequible para la clase media limeña. No vamos a reseñar el desarrollo de esta Semana Turística a través de los años. Sólo diremos, bajo este contexto, cómo se realizó la de 1999 (del 20 al 31 de agosto) (Trabajo de Campo: 29 y 30 -VIII-99).

La XXIX Feria Artesanal y Agropecuaria se realizó en un terreno adjunto a un coliseo a medio construir entre San Vicente e Imperial, lejos de ambos pueblos y de los turistas de Lima. Es la cuarta ubicación que tiene la feria desde sus inicios. El terreno estaba sin apisonar, con iluminación del alumbrado del coliseo. El Municipio lotizó los puestos cobrando 150 soles por cada uno de ellos, pero sólo un $60 \%$ fue ocupado. Actualmente el Municipio no ofrece ni alumbrado ferial (bombillas multicolores), ni ángulos ranurados, ni esteras para los puestos de modo que hay un completo caos en dicha feria. Cada uno levanta como puede un kiosco: con palos, plásticos, esteras, etc. Teniendo en cuenta la pobreza de los expositores se puede entender el resultado.

Los vendedores, ese año, fueron de comida (parrilladas) y licores, de artesanías, algunos vendedores de dulces norteños, mercadería coreana y juegos mecánicos. Se pudo, así mismo, notar la 
ausencia de comida típica. Los juegos de diversión, de pequeñas empresas que van de pueblo en pueblo, con pocas garantías de seguridad y calidad, ni siquiera consiguieron atraer la atención de los concurrentes. La autoridad organizadora ofreció, como todos los años, espectáculos nocturnos, pero estos eran fono mímicos preferentemente, a cargo de escolares y alumnos de institutos.

Tuvimos ocasión de ir varias veces al recinto ferial (en distintas horas). Había muy poco público, salvo en la noche de víspera de aniversario (domingo) y la noche del sábado. Pero se trataba de público con poco poder adquisitivo. Había no solamente ausencia de turistas nacionales sino también de la clase media local. Conversando con los vendedores supimos que existía un reclamo generalizado por la mala organización y el precio cobrado, que no iba a ser cubierto por negocios con tan pocas ventas. El resultado fue una feria fracasada.

El problema surge por la indiferencia del municipio a potenciar esta feria. Incluso, el cambio a un lugar tan inaccesible, nos demuestra el poco interés que existe en ella. El objetivo inicial de 1970, de ser un espacio de intercambio directo entre productores y consumidores, se ha perdido. El público consumidor, gente del lugar, ha ido incluso transformándose socio económicamente.

EIXXIX Festival de Arte Negro, ahora llamado "Nacional", debido a la pugna existente con Chincha por la cuna de dicho arte, y al reconocimiento del MITINCI en 1990 de la Semana Turística como de "convocatoria nacional", tampoco colmó nuestras expectativas. La organización fue mala en doble sentido: convocada para el sábado 29 a las 7 de la noche, luego de constantes retrasos se convocó a las 10, pero empezó dos horas después. Por otro lado, se indicaba una entrada general de 12 soles, para luego argumentarse que se trataba de la entrada "popular". La "VIP" era de 40 soles y la de "palco" 30. El lugar: el estadio municipal. Hubo poca gente, comparado con otros años, y muy poca concurrencia de Lima.

El desfile escolar del 30 de agosto no figuraba en la programación oficial, aunque finalmente se realizó.

Creemos que en el fondo la Semana Turística en su conjunto está en crisis, y con ella el mo- delo de promoción que nació en 1970. Esto tiene que ver con problemas de planificación, pero también con el hecho de que los distritos han asumido con festivales propios sus tradiciones. Además, la competencia de otras provincias (con festivales de folklore negro) le resta importancia a esta Semana. Es necesario decir que ésta nunca tuvo un éxito rotundo en su trayectoria, pero al menos trataba de cimentar y consolidar una tradición.

El reto actual es saber si vale la pena mantener la Semana. Los objetivos de captar turismo nacional no se cumplen desde hace varios años y demandan esfuerzos municipales enormes y de muchos negocios que ven mermados sus potenciales ingresos. El hecho de evaluar su viabilidad futura va en estrecha relación con saber si puede sustituirse por otro tipo de producto que implique seguir promocionando la cultura negra. El intento de dar difusión a un festival local "Cañete Negrito", hecho hace unos años, no resultó interesante. Por lo cual creemos que si se quiere promocionar este espacio de lo negro tendrá que ir por la vía de eventos más culturales y menos masivos, ya copados por los festivales de Chincha, Surco o el Callao.

En cuanto a la feria, creemos que como catalizador de la producción local no puede mantenerse. Ni siquiera tuvo éxito en 1999 un aparente Festival Provincial del Pisco, como parte de las actividades.

El reto es adecuar la Semana Turística con nuevos productos en función a los objetivos seculares o eliminarla y con ello buena parte de la tradición fundada en 1970. Tal vez sea hora de retomar productos distritales específicos y no provinciales.

Un sólo ejemplo: la festividad de San Vicente Mártir, nunca muy extendida, pero hoy minimizada, valdría la pena evaluarse como alternativa. Tal vez con una refundación de tradiciones, asumiendo su papel de ciudad moderna y mestiza San Vicente pueda encontrar una mejor captación de turistas. Tienen una buena red hotelera y de restaurantes para ello. Y promocionar quizá no tanto una Semana, sino un circuito turístico (el de las casas haciendas Arona, Montalván, Unanue) con una tradición negra.

Este circuito o la fiesta de San Vicente será el reconocimiento a la existencia de un corredor litoral, donde Cerro Azul, San Luis y otros 
lugares cercanos cuentan con recursos patrimoniales complementarios a integrar. Por supuesto, también en el futuro habrá que reconocer la existencia de un corredor transversal, hoy mal trabajado, con Lunahuaná como punto inicial, y no final, que se prolongue hasta la cabecera de Yauyos, reconociendo una tradición socio-histórica finisecular.

\section{Modelo dos}

Este nuevo papel dependiente de corredores litorales y futuros transversales, es la experiencia previa de pueblos y distritos como los de San Luis, Asia o Bujama. Hoy en día es claro que la especificidad de Bujama está dada por la venta de productos de panllevar en la carretera o por la atracción para un público de sector medio alto de balnearios como Las Totoritas, donde incluso se realizan conciertos, festivales de caballos de paso y actividades de gremios empresariales (CONFIEP, Copa Credicorp). En el caso de Asia, es importante la creciente urbanización de lotes para casas de playa (Cf. Cuadro 1) tanto como la aparición de clubes privados cerrados o casas granja especializadas, que le ha dado un determinado papel al interior del corredor. En ese sentido es famoso el caso de discotecas de playa como Ibiza, que entre diciembre y marzo, congrega a jóvenes que se movilizan entre los kilómetros 35 y 144. Ciertamente se trata de un papel donde el patrimonio natural (playa, mar, desierto) ha incentivado un tipo de actividad básicamente de verano, donde el empleo es temporal y marginal, pero si a ello agregamos el desarrollo de una serie de restaurantes de mariscos y chicharrones entre La Ensenada y Bujama, abiertos todo el año, y si tomamos en consideración que el corredor hace posible que la masa laboral se mueva estacional y geográficamente en un abanico de posibilidades de empleo (agricultura, servicios y transporte) podremos entender que esta asignación, a un papel de turismo basado en sol, playa y gastronomía, no debe ser entendido como determinante exclusivo del empleo de la micro región.

Se hace esta apreciación pues hasta hace un tiempo existía un enfoque errado del Municipio de Bujama, que reorientó recursos a promocionar otras posibilidades de productos turísticos, al crear por ejemplo un Festival del Plátano. En el año 2000 el festival fue un completo
Cuadro: Principales clubes de mar - Distrito de Asia

\begin{tabular}{|l|c|c|c|c|}
\hline Club de Playa & $\begin{array}{r}\text { Total } \\
\text { de lotes }\end{array}$ & $\begin{array}{c}\text { Lotes } \\
\text { vendidos }\end{array}$ & $\begin{array}{c}\text { Lotes } \\
\text { por } \\
\text { venderse }\end{array}$ & $\begin{array}{c}\text { Lotes } \\
\text { construidos }\end{array}$ \\
\hline Chocalla & 29 & 16 & 13 & 14 \\
La Isla & 79 & 79 & 0 & a36 \\
Los Flamencos & 86 & 71 & 15 & 60 \\
Las Arenas & 146 & 63 & 83 & 4 \\
Playa el Golf & 129 & 48 & 81 & 0 \\
Cayma & 70 & 70 & 0 & 67 \\
Las Brisas & 111 & 93 & 18 & 65 \\
Mar Azul & 29 & 29 & 0 & 5 \\
Las Palmas & 276 & 274 & 2 & 212 \\
Los Cocos & 102 & 102 & 0 & 94 \\
Sol y Mar & 89 & 89 & 0 & 58 \\
Playa del Sol & 243 & 204 & 39 & 81 \\
Playa Blanca & 194 & 192 & 2 & 111 \\
Bora Bora & 50 & 37 & 13 & 3 \\
Costa del Sol & 102 & 78 & 24 & 45 \\
Kapala & 101 & 93 & 8 & 77 \\
Palabritas & 133 & 24 & 109 & 6 \\
Playa Bonita & 167 & 126 & 41 & 52 \\
Gaviotas & 133 & 41 & 92 & 8 \\
Totales & 2269 & 1729 & 540 & 998 \\
\hline
\end{tabular}

fracaso. Y la crítica local fue en el sentido de que no todo el patrimonio era susceptible de ser convertido en oferta turística, y que era negarse a un proceso de reacomodo de actividades creadas por el corredor, donde Bujama participaba activamente, pero a otro nivel de actividades. Imagen pasiva frente a los hechos o no, lo cierto es que también el pueblo de San Luis ha aceptado esta generación de un espacio turístico novedoso, aunque sin tratar de reformar su papel al interior. Restaurantes de carretera como El Piloto, Gruta Azul y Cerro de Oro, se han convertido en elementos claves de la actividad gastronómica, como a su modo el templo católico colonial, restaurado hace unos pocos años, como una oferta material importante. Sin embargo en este caso, San Luis tiene otras posibilidades (Casa China, Casa hacienda de Santa Bárbara) que pueden integrarse a un eventual circuito de lugares histórico que unidos a los de otros distritos, puede ser una mejor manera de reforzar su inserción en ese novedoso espacio (Armas Asin 2002: Inventario patrimonial de la cuenca de Cañete. Anexos 1).

Pero si San Luis como Asia han aceptado su papel, y en el caso de San Luis puede ampliarlo en mejores condiciones, los ejemplos de Cerro Azul y Lunahuaná nos invitan a reflexionar sobre este corredor en términos estrictos del desempeño de los pueblos, pasivos o activos, a su interior.

\section{Modelo tres}

Cerro Azul, en 1870, no era más que una caleta de pescadores hasta que la necesidad de exportar azúcar de las prósperas haciendas del va- 
Ile, llevó a que se construyera un muelle. En 1926 se construyó otro, en el inicio del despegue algodonero. Cerro Azul se convirtió en un puerto obligado de vapores que tenian en el algodón su incentivo más importante. Con el considerable aumento de la población surgieron agencias de aduanas, comerciales, etc. Se creó la fiesta de San Pedro, patrón del puerto, así como gremios de ayuda mutua de obreros de puerto y pescadores. Sin embargo, no existía una conciencia clara del pasado, entre otras razones, porque era un pueblo relativamente nuevo. La historia de Cerro Azul empieza a fines del siglo XX. En la década del 60 la agricultura entra en un ciclo depresivo en el valle y el algodón empieza a contraer su quantum exportable. Finalmente, en 1971 se cierra el puerto de Cerro Azul, por no ser ya rentable para ENAPU (Empresa Nacional de Puertos). El pueblo entra en recesión económica: se mudan las agencias comerciales y de aduanas, se cierran negocios conexos y los pobladores tienen en la pesca artesanal, el peonaje en las tierras de la comunidad, o en la migración, sus mejores alternativas (Taki Onqoy: 1985).

Hay que entender el contexto de la década del 70 , con crisis de empleo prolongado e imposibilidad del lugar para ofertar una gama de empleos sostenible en el tiempo. Es interesante observar como el imaginario de la gente del lugar se fija en el pasado de bonanza. Testimonios fotográficos y relatos ayudan a esta vivencia del pasado en función a un presente incierto. Desde esta base, en 1983, empezará el nuevo auge del lugar.

Es exclusivamente la estructuración final del corredor litoral (con la nueva carretera Panamericana de doble vía como su columna vertebral), lo que sustenta la aparición de visitantes en el pueblo en pos de la playa de Puerto Viejo, de comprar o alquilar alguna casa de verano $y$, sobre todo, de jóvenes que descubren que el oleaje de Puerto Viejo sirve como escuela a tablistas aprendices. Esta llegada de limeños en los meses de verano permite la creación de puestos de trabajo. Hacia 1983, en la zona de Puerto Viejo, sólo existían el Hostal Cerro Azul (la Casa Rosada), de tres habitaciones y el restaurante-posada de la $\mathrm{Vda}$. de Sato. El primero captaba a familias que empezaban a ir al lugar y el segundo a campistas y tablistas (Vda. De Sato: Entrevista del 2-11-2000). No había desagüe y ellos construían sus silos con desembocadura a la acequia Chillón (acequia de desagüe de regadío). Poco a poco fueron surgiendo los hostales Marbella y Las Palmeras, y los restaurantes Gruta Azul y Marbella, en Puerto Viejo y otros hostales y restaurantes en el pueblo (a veinte metros). Muchos, como los propietarios del Hostal Cerro Azul, se beneficiaron de préstamos bancarios para ampliar sus negocios, con lo que aumentó la oferta de servicios (Sánchez: Entrevista del 2-XII-1999).

Este florecimiento de Cerro Azul, en verano, planteó dos problemas: la demanda estacionaria, que provocó un empleo también estacional sin posibilidad de ser contra balanceado el resto del año; y que fuera una demanda creada por el corredor litoral, un corredor que conforme se consolidara iría "descubriendo" a su interior nuevas alternativas de lugares de sol y playa. Es decir, la ventaja de Cerro Azul fue que existió una infraestructura inicial que le permitió recibir una demanda que apareció bruscamente, pero su drama fue la incapacidad de retenerla en el tiempo.

Aquí mucho tuvieron que jugar gobierno municipal y pobladores en su conjunto. El primero por su incapacidad de gestionar un plan orgánico de planeamiento urbano y turístico, salvo la administración de Ricardo Camacho (1984-87) que obtuvo de ENAPU el muelle (más no la rampa) pero que, sin una idea clara de qué hacer con él, sólo atinó a construir un muro de ladrillo encima para que la gente pudiera mirar el panorama, nadie hizo más por aprovechar la llegada masiva de visitantes en verano; mientras todos los accesorios del muelle (grúas, rieles) fueron vendidos en los años sucesivos. Segundo, los pobladores contaminaban las playas, con kioskos y comida, mientras las acequias de desagüe de irrigación, al sur y norte del pueblo, permanecían abiertas. Así, el público de diversos estratos económicos se fue perdiendo conforme año tras año las autoridades sanitarias empezaban a catalogar a Cerro Azul como zona de playas contaminadas (1990-1997). Este proceso corrió paralelo al hecho de que ningún otro organismo local hizo algo por una tarea de promoción.

Creemos que esto se debió a la fractura política y social de Cerro Azul, donde la incapacidad de articular una corriente de opinión planificadora, sumada al hecho más inconsciente de que, salvo el imaginario colectivo de viejos y periodistas, que recordaban un pasado en fotos sobre va- 
pores y épocas de exportación, no hubo una conformación orgánica de una idea patrimonial que, recogiendo estos aspectos, pasara a una exposición de ellos como plataforma agresiva de promoción turística. Es decir, a diferencia de San Vicente, e incluso de Chilca, no hubo una lectura patrimonial en clave turística.

Hacia inicios de ésta década los hostales mostraban altos índices de camas vacías, mientras algunos restaurantes tenían que reacondicionar su oferta a un público menos exigente, de familias y jóvenes de estrato popular, que siguió llegando a Cerro Azul. Desde entonces poco se ha hecho. Si bien, desde 1994 Puerto Viejo tiene desagüe y, se ha realizado una canalización bastante artesanal de la acequia Chillón gracias a la acción de su Junta de Vecinos. Mientras que en la actual administración de José Paine (Entrevista: 8-X-1999) se han asfaltado algunas vías de acceso y troncales del pueblo, no hay una idea clara sobre qué hacer con el viejo muelle, faro, calidad de servicios ciudadanos - agua, limpieza -, asfaltado del malecón, así como tampoco para una relación estrecha con el INC, administrador de los sitios arqueológicos de Centinela, EI Faro y Camacho. Existe sólo un esfuerzo aislado, de un grupo de empresarios del lugar-Pro Turismopara mejorar la calidad de sus servicios y promocionar Cerro Azul.

Este es un caso típico de cómo el corredor, como en otros lugares, creó demandas específicas que no fueron acompañadas de un esfuerzo activo de los órganos directrices de los lugareños, para consolidar su opción dentro de él.

\section{Modelo cuatro}

El caso de Lunahuaná es más reciente debido a que su experiencia fue fruto de la última expansión del corredor litoral (asfaltado en 1994 del tramo San Vicente-Imperial-Lunahuaná) y algo análogo sucedió, pero con una respuesta tardía aunque organizada de algunos pobladores. A inicios de la década de los 80 Lunahuaná no era más que un lugar de pequeños propietarios agricolas que se abastecía de una pequeña central eléctrica, con energía hasta las 6 de la tarde. No había turismo, la carretera era afirmada y los comités de camionetas eran el único medio de transporte. Las bodegas-restaurantes conocidas eran San Francisco y la anterior a lo que es hoy Sol \& Río, para viajeros en camino. Los jóvenes, sin mayores oportunidades de empleo en un lugar apartado, marchaban a Lima, Imperial o San Vicente. Aisladamente, en 1978, un empresario, Isidoro Castro, con intereses en hoteles y otras propiedades en el sur chico, construyó el Hotel Embassy, en una hectárea de terreno y con seis habitaciones. Era el deseo de explorar turísticamente una zona de sol todo el año, con un patrimonio natural rico - centrado en el río Cañete - y una gastronomía aceptable basada en vinos y camarones.

A este esfuerzo personal se unió el hecho de que, fruto del fortalecimiento del corredor litoral en los años 80 y con la afluencia de visitantes de Lima en busca de ecoturismo o turismo de aventuras, fueran llegando a fines de esa década muchos jóvenes. Ante esa apertura, clubes y asociaciones de canotaje, kayak y otros deportes del Urubamba, catalogaron al río Lunahuaná como zona de escuela para deportes de río, motivando una afluencia regular de visitantes. La respuesta, un tanto tímida de la municipalidad, fue crear en 1989, un Festival del Níspero, para mostrar el fruto principal de la zona. También la actividad de promoción del turismo a Lunahuaná que realizó Julián Cortez, editor de Contrapunto (Frecuencia Latina, 1992-1995) ayudó al proceso. A esto agreguemos la actividad de promoción de una entidad estatal como FOPTUR (1992), dentro de su plan de promoción de nuevos destinos turísticos. Toda esta lenta articulación del destino se consolidó en 1994 con la inauguración del asfaltado de la carretera entre Imperial y Lunahuaná (Espinoza: Entrevista 8-X-1999). Ese año, el Estado promocionó ocho destinos en el Perú, con Lunahuaná como oferta cercana a Lima, que contó con promoción televisiva (Marcos-Ibáñez: Entrevista 9-X1999; Arenas: Ibíd).

El resultado fue increible. Diez mil visitantes llegaron al Festival del Níspero. Pero saltó a colación una realidad: que si bien la oferta de hostales, restaurantes, clubes campestres, etc., había estado en ascenso en el periodo 19871994, Lunahuaná no estaba preparada para recibir esa cantidad de visitantes (Cámara de Turismo y Comercio de Lunahuaná: 1999). Los servicios colapsaron en esos días y en los fines de semanas siguientes, provocando que muchos, buscando siempre nuevas alternativas, no volvieran al lugar. 
Esa experiencia fue vital para el municipio, empresarios y demás organizaciones representativas del lugar. Si hasta entones no habían participado activamente en el proceso, pareció llegado el momento de hacerlo. Además había urgencia de mostrar un patrimonio en mejor perspectiva, más allá de lo que el Estado estaba haciendo. A fines de ese año, el 15 de diciembre, se organizó la Cámara de Turismo, con un grupo de empresarios jóvenes y profesionales, educados en Lima. La Cámara organizó un seminario de calidad del servicio y empezó a promocionar la imagen turística del lugar. La expansión de infraestructura continuó con nuevos restaurantes, hoteles y hostales, casas de pensión y clubes campestres (Armas Asin 2001: Cuadro. Guía breve de la cuenca de Cañete. Anexo 1). El discurso ya no apuntaba solamente a disfrutar del patrimonio natural (río, zona de aventuras) sino a apreciar el patrimonio histórico (Inkawasi, el templo católico) tenido en cuenta antes, pero no tan bien tratado. Al Festival del Níspero se unió otro en verano, el de la Uva y el Vino (actualmente del Vino y el Pisco), mostrando un abanico de posibilidades al lado del estímulo por los deportes de aventuras o los conciertos en el río.

El resultado fue una curva en ascenso de visitantes hasta fines de 1995. Pero en 1996 el número de hospedados y comensales de restaurantes empezó a decaer. La recesión de ese año, que luego se acompañó con el Fenómeno del Niño en 1998, y la recesión en los años siguientes, fueron las causas de esta crisis, así como las nuevas ofertas de otros destinos turísticos para los sectores A y B como San José, en Chincha, o de destinos nuevos en la Sierra de Lima, para los de $\mathrm{C}$ y D. Se sumó a esto el incremento de precios en los servicios en el período 1992-95 o la mala calidad de restaurantes y hostales, que alejó a buena parte de los visitantes. Todo ello implicó que la situación se volviera agobiante. Muchos restaurantes y hostales cerraron. Otros empezaron su ciclo de supervivencia aprovechando los fines de semana largos decretados por el gobierno o los feriados clásicos. Servicios básicamente dedicados a sectores C y D.

Esta prolongada crisis generó que muchos de los empresarios de la Cámara, sintiéndose poco representados por los gobiernos municipales, accedieran al poder en 1999. Básicamente, estos empresarios (Las Viñas, El Rosedal, Río
Alto, Bodega Santa María) han tratado de mejorar el destino turístico en base al aspecto urbano y propagandístico, para atraer y mantener un flujo de los sectores A y B. Han mejorado el asfalto y ornato de algunas calles y plazas, retirando la publicidad ruidosa y gráfica de grandes o pequeñas compañías que atentaban contra el deseo de una Lunahuaná para el descanso, y han potenciado el Festival del Vino y el Pisco de la tercera semana de marzo y el Festival del Níspero del mes de Octubre. De la mano de este proceso su discurso patrimonial apunta a poner en valor los aspectos agrícolas, gastronómicos y naturales de la zona, bajo la connotación de ser un lugar de descanso y cuna del Curacazgo de Lunahuaná (Inkawasi).

Es interesante ver como en este caso grupos especificos de intereses del lugar, han tratado de modificar aspectos de la creación del espacio turístico, que nació de un deseo gubernamental y se consolidó en el corredor litoral.

\section{Modelo cinco}

Casos como éste, al lado de los de Asia - San Luis, relativamente pasivos en las actitudes ante la perspectiva de oportunidad, aunque sin el resultado trágico de Cerro Azul, deben entenderse al lado de otros, como los de Chilca, de oportunidades mínimas sin reacciones manifiestas. Es elocuente en ese contexto, el ejemplo de Mala que fue hasta 1983 un poblado próspero, y aunque la crisis agraria modificó la estructura laboral de la zona, las nuevas oportunidades económicas en el sector servicios, básicamente ligadas a la Panamericana Sur, permitieron amortiguar su impacto. Sin embargo, la nueva ruta de la autovía, que seguía por Bujama y no por Mala -aún cuando se abrió un camino de entrada-, significó una modificación micro espacial dentro de los poblados del distrito. Bujama ganó importancia, se construyeron en sus playas balnearios y clubes, mientras Mala se unió al letargo secular de su cabecera. La población empezó a migrar al litoral y muchos negocios se derrumbaron. Por ello, si hasta 1983 había alguna perspectiva de promocionar el patrimonio de Mala -básicamente gastronómicoluego fue una tarea titánica, de la cual curiosamente hasta el momento poco se ha hecho en términos de políticas municipales. 


\section{Ejemplos sin modelar}

En cuanto a las cabeceras de las cuencas de Chilca, Mala y Cañete, debemos decir que estas se vieron directamente afectadas por un peculiar proceso socio-histórico (Fonseca: 1983; Mayer y Fonseca: 1979; ONERN: 1970). Hemos dicho que en la cabecera de Chilca, Santo Domingo de los Olleros quedó integrado a Huarochirí, y éste a su vez a Lima, a través de la carretera de Cieneguilla; como es el caso también de Santo Domingo de Quinti, San Pedro de Huancaya, San Juan de Tantaranche o Tanta, lugares de la cabecera de Mala. En estos lugares, la política seguida por sus municipios distritales y el provincial de Huarochirí, como por diversos organismos locales, se ha caracterizado por una carencia notable de tareas de promoción. Existe una general ausencia de visitantes al lugar. En los últimos años, algo análogo sucedió en la cabecera de Cañete, dependiente de la provincia de Yauyos. El corredor litoral había integrado Lunahuaná a su seno, pero de allí hasta Huancaya y Vitis, en el extremo norte del camino y de la cabecera de la cuenca, seguía sin integrarse. Sin embargo, la declaración en 1996 de Zona de Reserva Turística Nacional (ZRTN) de la cabecera de Cañete, como la inversión gubernamental (inacabada) de un hospedaje en Vilca, llevó a valorar un circuito turístico que conecta Lunahuaná con Yauyos, Tupe, Laraos, Alis, Miraflores, Huancaya y Vilca. De la comunidad de Tupe, famosa por sus trajes, pasando por la andenería, tejidos y la iglesia colonial de Laraos, las piscigranjas de Alis, hasta el sistema de lagunas, grandes nevados y truchas de Huancaya y Vitis. Empero, este espacio turístico es sólo embrionario. Falta asfaltar la carretera entre Lunahuaná y Huancayo, hay escasez de hoteles (sólo en Yauyos capital hay un albergue municipal con 39 camas y 2 particulares con 20), los restaurantes son de mala calidad y no hay autoservicios de combustibles. La escasez de visitantes es palpable, salvo en agosto, mes de aniversarios de fundación o fiestas patronales en Yauyos y algunos pueblos, pero son sobre todo yauyinos residentes en Lima. Seis a ocho horas en auto separa Huancaya de Lima, aunque cerca de dieciséis en ómnibus. El gran dilema es que Yauyos presenta hoy el espectáculo de una provincia seccionada en muchas áreas dependientes, sea de Huarochirí, Mala, Omas o Cañete. Sobre esta estructura se está creando este novedoso espacio turístico.

\section{Modelos, espacios turísticos y fragmentación patrimonial}

El corredor litoral, la ruta transversal Lunahuaná-Huancaya, la zona de la cabecera de Mala y Chilca, unidos a la carretera de Cieneguilla, son los espacios turísticos formados en la actualidad. Bien decíamos que son resultado de construcciones específicas que tienen en el centralismo histórico y en las sucesivas modificaciones espaciales sus pilares más importantes. Ahora bien, el corredor litoral es el espacio mejor desarrollado, pues el ligado a Huarochirí tanto como el del eje Lunahuaná-Huancaya están limitados por problemas de asfaltado e infraestructura social y turística mínimas. Han sido además muy postergados, fruto de la crisis secular de las cabeceras. Sin embargo, el derrotero histórico actual las ha articulado como potenciales espacios de irradiación económica.

En otro sentido, estos espacios han determinado un proceso donde la lectura patrimonial ha tenido la característica de ser profundamente centralista, litoral y con sesgos de exaltación sobre los lugares que se han estructurado (ciertamente el corredor litoral). Con la aparición de nuevos espacios embrionarios, otras lecturas patrimoniales, basadas en el descubrimiento de los legados materiales serranos, gastronómicos y festivos, irrumpen con fuerza. En el corredor litoral mismo, una lectura del pasado muy tradicional, así como los propios cambios sociales y políticos contemporáneos han llevado a que se amplíe el espectro de patrimonio y de lo susceptible de ser convertido en producto turístico (Armas Asín 2002: Cap. 3).

Los casos descritos nos muestran como la gastronomía maleña (chicharrones, panes de Mala) en la zona de La Ensenada y Bujama, tanto como el patrimonio natural de playas y pampas para motocross y otros deportes de aventuras y actividades de distracción, han ampliado el concepto de lo patrimonial en Asia, Bujama o Lunahuaná, donde hasta hace unos años estaba circunscrito básicamente a la fecha de fundación distrital o la visita a algún lugar arqueológico. Lo ocurrido con esos lugares supone una ampliación que a su vez es fruto de la consolidación del corredor. Pero esta creación de patrimonio es efecto y no causa, es decir, la lectura patrimonial justifica el hecho elocuente de esta aparición y su conversión simultánea en producto turístico. Pero, ¿quién estructura la lectura patrimonial en estos lugares? Pues 
ciertamente el Estado, en primer término, promoviendo «atractivos» bajo el concepto de más y mejores lugares cercanos a Lima para el turismo interno, y la promesa del efecto multiplicador de la economía por ampliación de la infraestructura (carreteras, paradores). El Estado tiene un concepto del patrimonio claramente establecido como producto turístico, con un sentido relativamente amplio. A otro nivel están los gobiernos locales, como la diversidad de entidades de la zona, que estructuran un discurso reinvindicativo del patrimonio. Lo hemos apreciado en los casos de Chilca o Cerro Azul, y del mismo San Vicente, o en un sentido más amplio de toda la provincia de Cañete o Yauyos.

Sin embargo, en casos como el de Lunahuaná hay un deseo de las instancias locales por ampliar el sentido del patrimonio como producto turístico a otros campos y objetos. Sin embargo, no siempre estas actitudes son viables. Mucho depende de la solidez de su base discursiva: los objetos o campos a patrimonializar. Con respecto a Chilca es claro que su patrimonio es viable como fuente de atracción de visitantes, pero solamente si se crea un impacto consistente ligado a la promoción de los atractivos generales de todo el corredor. Idéntica actitud encontramos en San Vicente. Pero casos como los de Cerro Azul o Mala nos invitan a reflexionar sobre cómo el corredor, ente estructurador, puede dar enormes oportunidades económicas al posibilitar la oferta patrimonial a un lugar (Cerro Azul) y negársela a otro (Mala). Sin embargo también es claro que ampliar la gama del patrimonio y su oferta en un lugar no implica, por la misma dinámica del proceso, que éste sea un efecto permanente: el auge y caída de Cerro Azul nos muestra los derroteros asombrosos de cómo puede ir proyectándose un espacio turístico. Pero más aún, nos muestra cómo cuando hay ausencias de toma de conciencia del patrimonializar, en entidades que no sea sólo el Estado, puede ser nefasto. Hay aquí una lección profunda: la de entender que se necesita la activa participación de gobiernos y entidades locales en general para mantener un nivel aceptable de inserción de un determinado espacio. El ejemplo de Lunahuaná, con un empresariado y comunidad activa en hacer rentable en el tiempo inicio logrado por el Estado, es elocuente.

Otro punto interesante es el intento, paradójicamente como fruto de la apertura del corredor litoral y de los cambios mentales contemporáneos, de crear nuevos espacios turísticos en la cabecera de Cañete, Chilca y Mala. De la mano de jóvenes interesados en el turismo ecológico, de aventura o de familias en busca de un fin de semana de descanso. ¿Estos nuevos espacios entran en contradicción con el corredor? Creemos que parcialmente. Tanto como en la toma de posición de pobladores y entidades de la costa. En ese sentido, asfaltado de vías y equipamiento de infraestructura diversa ayudarán lentamente. De todas maneras, en lo inmediato no dejan de ser un cuello de botella estas contradicciones entre espacios. Como también lo es la lucha dialéctica de las capitales de provincia (San Vicente, Yauyos) con los distritos, buscando las primeras imponer una lectura patrimonial basada en su preeminencia sobre el resto. Centralismo a nivel regional, hace que exista (lo hemos revisado en el caso de San Vicente) otra lectura patrimonial.

Esto nos lleva a postular la presencia de una fragmentación patrimonial muy intensa en nuestra área de estudio. Creada por el proceso histórico, por la acción directa del Estado, de las capitales provinciales, o promovida por la acción local distrital. Esta fragmentación patrimonial está a su vez ligada a una fragmentación espacial. Así como al asfaltado o creación de nueva infraestructura en las cabeceras que busquen parcialmente revivir conceptos de cuencas. ¿Ello se trasformará en una lectura patrimonial nueva, que supere estas contradicciones o lleve a la imposición de una lectura determinada sobre las ya existentes? Son elucubraciones difíciles de avalar. 


\section{BIBLIOGRAFÍA}

\section{A. Material primario}

\section{Entrevistas}

ESPINOZA, J. A.

NAPA, L.

PAINE, José

RUEDA, Numa

SANCHEZ, Alicia

SATO, Viuda de
Entrevista del 08/10/1999

Entrevista del 13/09/1999

Entrevista del 08/10/1999

Entrevista del 13/09/1999

Entrevista del 02/12/1999

Entrevista del 02/02/2000

\section{Informes}

1999 Informe de Trabajo de Campo, del 29 y $30 /$ 08/1999.

1999 Encuesta de Mercado Laboral en Chilca.

1998 Informe Técnico del Arq. César Levano. S.a.f.

\section{B. Material secundario}

ARMAS ASÍN, Fernando

2002 Sur Chico / Lima. Espacio y patrimonio Lima, Instituto de Investigaciones. UPSMP. Pro Manuscrito

Cámara de turismo y comercio de Lunahuaná 1999 Ficha de Descripción del Distrito de Lunahuaná y su Crecimiento en Infraestructura de Servicios Turísticos hasta el año 1999, s.a.

CARDENAS, Miguel.

1999 Cañete: Información Geográfica, Históricay Estadística. Cañete, s.a.

CASTRO CHERO, Karim

S.F. Inventario Turístico de Chilca. s.a.

CORREA, Luciano.

1978 Historia de la Industria Azucarera del Valle de Cañete. Lima, UNAM.

CHILCA, Municipalidad.

1999 Guia Turística de Chilca. Municipalidad Distrital de Chilca. S.A.

CHILCA, Municipalidad.

S.F. $\quad 186^{\circ}$ Aniversario del Primer Cabildo de Chilca.Chilca, Municipalidad Distrital.

FONSECA, César

1983 "El Culto Comunal del Agua en al Cuenca del Río Cañete." En: Allpanchis 22, XIX. Cuzco.

LUYO SANCHEZ, Juan.

1981 Cañete en Cifras. Cañete, La Voz del Pueblo.

MAYER, Enrique

1979 Sistemas agrarios en la cuenca del río Cañete. Lima, ONERN.

ONERN

1970 Inventario, Evaluación y Uso Racional de los Recursos Naturales de la Costa. Cuenca del Río Cañete. Lima. ONERN.

\section{ONERN}

1976 Inventario, Evaluación y Uso Racional de los Recursos Naturales de la Costa. Cuenca del los Ríos Chilca, Mala y Asia. Lima. ONERN.

\section{TAKI ONQOY}

1985 Cerro Azul y su Historia. Lima, CELADEC.

CORREA, Luciano.

1978 Historia de la Industria Azucarera del Valle de Cañete. Lima, UNAM.

CHILCA, Municipalidad.

1999 Guia Turística de Chilca. Municipalidad Distrital de Chilca. S.A.

CHILCA, Municipalidad.

S.F. $186^{\circ}$ Aniversario del Primer Cabildo de Chilca. Chilca, Municipalidad Distrital.

FONSECA, César

1983 "El Culto Comunal del Agua en al Cuenca del Río Cañete." En: Allpanchis 22, XIX. Cuzco.

LUYO SANCHEZ, Juan.

1981 Cañete en Cifras. Cañete, La Voz del Pueblo. 
MAYER, Enrique

1979 Sistemas agrarios en la cuenca del río Cañete. Lima, ONERN.

\section{ONERN}

1970 Inventario, Evaluación y Uso Racional de los Recursos Naturales de la Costa. Cuenca del Río Cañete. Lima. ONERN.

\section{ONERN}

1976 Inventario, Evaluación y Uso Racional de los Recursos Naturales de la Costa. Cuenca del los Ríos Chilca, Mala y Asia. Lima. ONERN.

\section{TAKI ONQOY}

1985 Cerro Azul y su Historia. Lima, CELADEC. 